\title{
From a passive to an active house
}

\author{
Charlotta Isaksson \\ Department of education, communication and learning, University of Gothenburg, Gothenburg, Sweden \\ Tel: +46709-708377,E-mail: charlotta.isaksson@ped.gu.se
}

\begin{abstract}
This paper presents a study on how the energy concept for passive houses is interpreted and used in the daily life of householders. It examines the gradual process by which householders both adapt to and shape passive house technology in their material and social context, thus creating a comfortable home. The theoretical concept of domestication was used in order to understand this process. The empirical material was based on qualitative interviews with residents of passive houses in Sweden. Two rounds of interviews were conducted with 22 informants from 16 households and 21 informants from 15 households. The results show that from a user perspective, the passive house is an active house. An active house has event-based heating. The indoor temperature changes in relation to the household's daily routines and rhythms, their everyday activities and use of appliances. Event-based heating creates different conditions for individual households and alters the meaning of many daily chores. Another result shows that domestication of the passive house concept is a dynamic and long-term process, where the view of indoor temperature and use of technologies change over time. Examining the domestication of passive houses leads to a more informed design process and an opportunity to educate new residents.
\end{abstract}

Keywords: Passive houses, Domestication, Households, Space heating

\section{Introduction}

Passive houses have been highlighted as an important solution to the problems associated_with high energy use for heating in the built environment [1] [2]. The last ten years have witnessed a considerable increase in the market for passive houses in north and central Europe, which is proof of the value of this energy concept. In other words, it has passed the trials connected with its use. The energy use of passive houses has been found to be far below the average and papers have been published about satisfied residents, containing descriptions of comfortable climate conditions [3]. However, the results often show a static product which may be misleading for new residents. Expressed differently, a common impression is that the user simply and immediately adapts to what is offered. The users are seen as passive receivers of the technology. As with any new technology, residents of a recently acquired passive house are confronted by unfamiliar features, to which they have to accustom themselves in one way or another. This paper presents a study of how the energy concept for passive houses is interpreted and used in the daily life of householders. It examines the gradual process in which the householders both adapt to and shape the passive house technology in their material and social context, thus creating a comfortable home. The focus is on the energy concept for heating these buildings:

There are three main factors that affect the amount of energy required for heating a building: 1) the quality of the envelope of the building, including heat exchange. 2) The efficiency of the heating system and 3) the householders' activities, preferences and needs related to heating [4]. Considering the first factor, typical components and requirements for a passive house are a very well insulated and tight building envelope combined with a ventilation system equipped with an efficient heat exchanger. With regard to factor two, the heating of the building is supposed to be mainly managed by "passive" sources such as solar irradiation, human body heat and the residents' use of appliances and lighting [3]. In the case of the energy concept of passive houses, a grouping between factors two and three is made. Through their body heat and use of household appliances, the members of the household constitute a 
major part of the heating system. The research questions are: How is the energy concept for heating the building interpreted from a user perspective? How do the residents become accustomed to the energy concept of passive houses? The paper specifically contributes to an understanding of the passive house concept from a user perspective. It provides an understanding of the dynamic yet gradual process of domesticating new technologies. The paper begins with an introduction of the concept of domestication, which is used to describe how passive house technology is gradually integrated into the everyday life of users. The next section outlines the empirical method and data. Thereafter, the results of the two research questions are presented. Finally, conclusions are drawn that highlight the importance of examining the gradual implementation of energy efficient technology.

\section{Theoretical approach}

This paper examines the domestication of the energy concept in passive houses. In the concept of domestication, the users are regarded as active agents in shaping the way technology is used and, in the long term, its future development [5]. In this paper domestication is regarded as a process, in which the individual both adapts to and shapes the novel technology in his/her social and material context [6] [7]. The user undertakes both practical and symbolic work in relation to the technology as well as learns how to handle it in an appropriate way. In this process, the reciprocal influence of the user and the technology is not totally predictable. Thus, the passive house concept leads to a change in how the heating of buildings is achieved. This change is ultimately manifested in the social environment where the technology is used and particular meanings are assigned [8].

In this process the users' relationship to the technology changes over time. For instance, Silverstone et al. analysed the domestication of new technology by means of four non-discrete phases [5]. The first phase occurs when the technology is introduced to the domestic environment. The second is when the technology is assigned a physical space in the home, where norms and values attached to the technology are highlighted, and the initial use begins. The third phase emphasises the subsequent use of the technology and how it is incorporated and fitted into the routines of daily life. Finally, the fourth phase describes the communication between the household and the outside world. By demonstrating different phases, Silverstone et al. highlighted the integration of a new technology as a dynamic and changeable process, where the users' relationship to and strategies associated with the technology vary. Thus, the interplay with technology is reviewed and reassessed over time [7]. In a similar vein, Lehtonen interpreted the domestication of new technologies, although he studied the phases of domestication as a set of trials in which the capabilities of the users and the technologies were tested in multiple ways [9]. For instance, one type of test is the process of learning what the technologies can do and what the user can do with them, while another is the process of judging that the technology is no longer of any value. In this paper, I will examine the gradual integration of the energy concept for passive houses in relation to the householders' previous situation and collective norms in society. Passive house technology provides a new way of heating buildings, and these features are compared with what the residents were used to in their former accommodation and the houses of others.

\section{Methodology}

In-depth interviews were conducted with residents living in the first passive houses in Sweden situated south of Gothenburg. The buildings, which were completed in 2001 and were sold as co-operative flats, consist of 20 terraced houses divided into four blocks. Each house is 120 $\mathrm{m}^{2}$ and comprises a ground floor, an upper floor and an attic. The south side of the houses has 
large window areas, while the north facing side has smaller windows. The passive house standard has a maximum space heating load of $10 \mathrm{~W} / \mathrm{m}^{2}$ [10]. In these buildings a $900 \mathrm{~W}$ integrated heater connected to the supply air is intended to cover some of the space heating demand during cold periods. Moreover, solar collectors were installed on the roofs to cover parts of the hot water demand. The measured mean values from all of the passive houses during the second year, show an indoor temperature of $23{ }^{\circ} \mathrm{C}$ (from two measuring points central in the buildings). The occupants stated that the average temperature was about 20$21^{\circ} \mathrm{C}$ [11]. It is worth noticing that these temperatures do not say anything about the heat sources used.

The interviews were conducted in two sessions, 2002 and 2005, with 22 members of 16 households and 21 members of 15 households. (During both rounds of interviews one of the apartments was uninhabited and used for research and demonstration purposes). The interviews took place in the householders' homes and lasted between one and two hours, depending on how many family members were present. In six of the interviews, both in 2002 and 2005, two adults from each household were present, while one adult participated in the remaining interviews. In total, 31 informants took part in the study and 12 were interviewed twice. The interviews were audio-taped and later transcribed for analysis. A quoted informant is referenced by an assumed name and the interview year, since they participated anonymously in the investigation [12].

Qualitative interviews were chosen, since they are successful for promoting a user-centred approach where the point of departure is the residents' own perception of how they use and relate to the technology. The strength of qualitative interviews is their ability to capture a variety of opinions and provide a multifaceted and comprehensive picture of the phenomenon studied [13]. The main topic of the interviews was heat comfort and different ways of managing the heating in passive house apartments. Investigations and evaluations of heat comfort often fail to consider the residents' perceptions and activities, instead relying on physical measurements or different statistical standards. Thus, the users are seen as passive recipients of an indoor climate achieved by means of installations such as heating systems [14]. However, this paper is more in line with the so called "adaptive approach" where the residents actively adapt to certain conditions with the help of building technologies and other resources such as clothes, slippers, candles etc [15]. Moreover, the users' management of heating is situated in a social and cultural context that shapes their handling of the heating and what they consider to be an acceptable indoor temperature [14].

\section{Result}

In the energy concept of passive houses, the residents are explicitly described as being part of the heating system by means of their use of household appliances and human body heat. The first section briefly considers how this heating system is interpreted from a user perspective, whereas the second analyses its gradual integration into the everyday life of householders.

\subsection{Event-based heating}

When addressing how the households perceive indoor temperature, some dominant features become evident. One of them is fluctuating indoor temperatures [16]. The temperature in passive houses changes during the day. In the morning when the household wakes up, it is warmer on the second floor where the bedrooms are situated, but colder on the first floor where the living room and kitchen are located. Nevertheless, the temperature increases rather quickly when the family gathers on the first floor and household appliances are used for 
making breakfast. The temperature decreases after the members of the household leave the building for work and school, but rises again shortly after they return to the building in the afternoon. Whether it is warmer on the second or first floor in the evening when everybody is at home appears on first sight to be an issue of where the family members usually are. This is interesting, as the passive house concept seems to change the way the indoor temperature is normally perceived to function.

In a cross-cultural study between Norway and Japan, Wilhite et al. identified differences in how buildings are heated [17]. Norwegians tend to heat the whole building and have a relatively constant indoor temperature, whereas the Japanese, only tend to heat the room they occupy. The culture in Sweden is closer to that of Norway, but the energy concept has led to a change. This partly means a shift from heating the whole building to heating the room in which one usually finds oneself. However, the indoor temperature in passive houses does not only fluctuate during the day. Another striking feature is the difference in temperatures between the weekend and weekdays, since to a large extent the members of the household are at home during the weekend: "When one is at home and doing things, washing, using the dish washer, cooking and suchlike, I think that there is good heat circulation and it feels warm" (Frida 02). Frida's description does not really coincide with the heating culture mentioned above. It indicates something different from generating heat for the rooms that the family members normally use, namely a heating system made up of human activities; an event-based heating system. Heat is supplied when they are engaged in daily activities such as cooking and cleaning, or when they have guests for dinner, thus the term "passive house" is misleading. From a user perspective, it is an "active house", where the heat is generated from the everyday activities of the residents.

Two different tendencies can be discerned within event-based heating. One is that the more activities the household members engage in, the warmer it becomes. That is, people and their participation in everyday activities at home "add" heat for the benefit of each other. The other is that it becomes cooler when there is no one or only a few household members at home or at the times when the household members change location in the house to a place where they have not been for a long time. This mainly concerns going from the second to the first floor or vice versa, such as in the example above when the householders come down to the first floor in the morning.

The concept of domestication underlines the fact that the use and meaning of the technology is integrated and shaped by the social milieu, everyday rhythms and routines of the households [5]. Domestication of the energy concept for passive houses gives rise to an eventbased heating that is highly dependent on the social milieu and activities of the households. An event-based heating creates different conditions for different households. Smaller households may not generate enough body heat or heat from human activities. Moreover, the result shows that households in which members perform many activities outside the home will have difficulty making the energy concept work adequately, i.e. it does not fit their daily routines and rhythms. In addition, there is a relatively large difference between living in an apartment located at the gable end and living in the middle apartment of the passive house, since heat was better retained in the middle one. In conclusion, the concept generally better fits a four-person household in a middle apartment when the residents spend a considerable amount of time at home. However, the individual conditions of those living in the apartment are also important to consider. For instance, an addition to the family means more body heat as well as increased use of household appliances, which makes it warmer indoors. 
Simultaneously, the responsibility that comes with the new family member often leads to a demand for a warmer indoor climate.

\subsection{Domestication of the energy concept for passive houses}

The following subsections consider the gradual process by which householders both adapt to and shape the content of the event-based heating by means of four types of interplay between their previous experience and the new way of handling heating. In particular, the first three reveal how the householders use of technologies and their view of the indoor temperature changes over time.

\subsubsection{Re-creating an acceptable heat comfort}

In the 2005 interview session, when the residents looked back on their years in the passive houses, the first two were described as more troublesome, slightly cooler and sometimes too cold. The resources offered by the energy concept were simply not regarded as sufficient to create a comfortable indoor temperature at home. This led to frequent use of other resources not compatible with the energy concept - such as external electric heaters: "We used fan heaters. We had one downstairs and one upstairs with the timer set for three times per day. Because we didn't have the temperature we wanted” (Maria 02). Maria's family was used to a temperature of around $23-24^{\circ} \mathrm{C}$ from her previous home, which she tried to re-create in the passive house with the aid of electric heaters. The term re-creating indicates that the difference between the new way of heating the building and the household members' previous experience is large and also perceived as such and that the members somehow try to recreate the former conditions.

Furthermore, the resources used for re-creating a comfortable indoor temperature were not limited to external heaters. Domestication of technology may give rise to meaning and usage not intended by the producers [5]. One such consequence of the event-based heating is that it alters the meaning of many daily chores at home, such as washing dishes and drying clothes: "If I put the dishwasher on it gets warm" stated Hanna (05), one of the informants. The tumble drier is "really nice and warm" said Maria (02). The dishwasher and the tumble drier were not only appliances that could dry clothes and clean dishes, they also meant a warm and comfortable indoor temperature during the cold winter months. In general, this "double meaning" of the use of household appliances did not stimulate the conservation of energy and an opposite tendency was found. For example, households sometimes washed clothes or turned on the oven, not because they needed to wash or cook, but because the appliances contributed to a comfortable indoor temperature. Use of other resources compatible with the energy concept, such as extra clothing, was not acceptable to these residents.

\subsubsection{Re-evaluation of the indoor heat}

Thus during the first year, the households where unfamiliar with living in a passive house and many felt that the indoor temperature was to some extent too low. However, while the use of external radiators occurred relatively frequently during the first and second winter in many of the apartments, they became much less common in the following years. In addition, as time passed, the indoor temperature was perceived as normal. A change in how they related to the event-based heating obviously occurred: I think that I have got used to the temperature, that it's a little cooler. It is really too hot at work" (Hannes 05). As Hannes put it, the change in perception also involved an aspect of re-evaluation of the indoor temperature where previous conditions were regarded as less favourable in the light of the present ones. 
One interesting reason for this change can be found in what Berner defines as a "perceptual and bodily adjustment" [18]. Berner, who studied industrial workers' interaction with machines, described it as a process where the human being is forced to "filter out" what one would normally notice in a new environment, such as smell, sound and the speed of new machines etc. It happens simultaneously, as one has to learn how to recognize and act on the basis of new phenomena of which one was previously unaware. The perceptual adjustment to event-based heating occurs by living in the passive house and noticing how the indoor heat changes in relation to the activities and daily rhythms of the household. Moreover, by comparing the heat generating capacity of various technologies and appliances, the household becomes aware of the most suitable method of heating the building. This was demonstrated by Nina who reported that "the effect is better with the candles than with household appliances" or when Johanna compared the use of candles with that of electric light, concluding that the former was more effective. Such comparisons probably facilitate the handling of the heating in the passive house. Other reasons for the change in how the energy concept of passive houses was interpreted are the household's increasing competence in handling the integrated heater in the ventilation system and improved functioning of the energy technology installations. (During the first two years, the ventilation system sometimes malfunctioned). Moreover, some of the informants mentioned the damp remaining from the construction of the houses, which they said gradually vanished. These issues are beyond the scope of this paper, but they all point to the fact that the interplay with technology is reviewed and reassessed by the residents over time [7].

\subsubsection{Familiar circumstances}

One explanation for their re-evaluation of what an acceptable indoor temperature should be is found in the references to other people's homes, and what is considered a normal indoor climate. "They [the cold floors] made me react a little at first but on the other hand they are cold in other houses too and I don't think they are colder here than in other terraced houses" (Caroline 02). Here, the similarities between the heat comfort in passive houses and other buildings were highlighted, pointing to the existence of ordinary and familiar aspects in the confrontation with the new way of handling heating. The term ordinary indicates that the routines for handling indoor comfort, such as the use of slippers and cardigans, as well as the perception of the indoor temperature are similar to what the household members are used to or are common in society in general.

\subsubsection{Innovative ways of managing indoor heat}

A re-evaluation of the indoor temperature also highlights positive differences. Although the differences between the household members' previous ways of handling heating and the passive house energy concept are large, they are not necessarily seen as negative. As Bakardjieva who studied the use of internet stated, technologies are often used as innovative tools for changing the present circumstances [19]. Thus, passive house technology becomes interpreted as an innovative tool for changing previous ways of handling indoor heat and creating a more pleasant and comfortable indoor temperature. For Paulina, this was the case from an early stage: "As I left a house that was really very warm I thought that it was more comfortable to live in a house where I can put extra clothes on instead of a house where it's too hot" (Paulina 02). The differences outlined above are overcome by the fact that the energy concept for passive houses leads to a desirable change. In addition, resources such as clothes, slippers and blankets are regarded as "nice and cosy" and as a prerequisite for a healthier and comfortable indoor climate. 
Other examples of new routines, or new ways of thinking about indoor climate in buildings, are keeping the heat inside by quickly closing the door when entering and seldom airing. This is a new habit that is partly due to the limited possibilities of heating the passive house. Moreover, as highlighted above, the household appliances have become "producers of heat." Another aspect of this is that the householders utilized the heat from the appliances, for instance by facilitating the spread of heat by opening interior doors. These activities are not a "passive" adaptation to the circumstances in a passive house. From the perspective of the householders it is an active process and interpreted as the most appropriate way to handle indoor heat. Other desirable changes that come with the passive house energy concept are an improved economic situation as well as environmental protection. The former included feelings of participation in fulfilling the intentions of the product developers in the creation of an energy efficient home.

\section{Conclusion}

This paper has examined the domestication of the energy concept for passive houses. Using the term 'event based heating' I have highlighted some important features that newcomers to passive houses may encounter. The gradual process of getting used to the energy concept has been explored by means of four types of interplay between the householders' previous experiences and the new way of handling heating influenced by the energy concept. In a sense, these types reflect what users may be confronted by when leaving old technology behind and experiencing new. Some features are missing, which the householders try to compensate for, whereas others are improved or fairly similar to what they were used to. Nevertheless, their relationship to these features is changeable and might be re-evaluated over time. It is important to identify the content and development of the reciprocal influence between the energy related technology and the user. For instance, does living in passive houses give rise to non-energy efficient routines in relation to household appliances? The result of this study indicates that it does, which in part questions the establishment of a maximum space heating load of $10 \mathrm{~W} / \mathrm{m}^{2}$. However, there are also long term tendencies that demonstrate the creation of a more environmentally friendly view of indoor temperature as well as routines in line with an energy efficient way of life. By examining the domestication of the energy concept in passive houses, an improved understanding of user practice in these buildings can be developed. This would lead to a more informed design process as well as an opportunity to provide information to new residents of passive houses.

\section{References}

[1] Statens offentliga utredningar, Vägen till ett energieffektivare Sverige. Slutbetänkande av Energieffektiviseringsutredningen, (Government official reports. The road to an energyefficient Sweden. Final report of Energy-efficiency Inquiry), SOU 2008:110.

[2] European Parliament resolution of 31 January 2008 on an Action Plan for Energy Efficiency: Realising the Potential (2007/2106(INI)).

[3] J. Schnieders \& A. Hermelink, CEPHEUS results: measurements and occupants' satisfaction provide evidence for Passive Houses being an option for sustainable building, Energy Policy 34, 2006, pp 151-171.

[4] A-L. Lindén, Värme i bostäder. En kvantitativ analys av energiförbrukning. (Heating in homes. A Quantitative analysis of energy consumption) Elforsk rapport 07:61, 2007.

[5] R. Silverstone, E. Hirsch \& D. Morley, Information and communication technologies and the moral economy of the household, in R. Silverstone \& E. Hirsch (eds) Consuming technology: Media and Information in Domestic Spaces. Routledge, 1992, pp 15-31. 
[6] M. Lie \& K. H. Sørensen, Making technology our own, Scandinavian University Press, 1996.

[7] K. Sørensen, Domestication: the enactment of technology, in T. Berker et al. (eds) Domestication of Media and Technology, Open University Press, 2006, pp 40-57.

[8] C. Isaksson, Uthålligt lärande om värmen? Domesticering av energiteknik i passivhus, (Sustainable learning about indoor heat? Domesticating energy technology in passive houses.), Department of Thematic Studies- Technology and social change, Linköping University, Sweden, 2009.

[9] T. Lehtonen, The domestication of new Technologies as a Set of Trials, Journal of Consumer Culture 3, 2003, pp 363-385.

[10] W. Feist, J. Schnieders, V. Dorer. \& A. Haas, Re-inventing air heating: Convenient and comfortable within the frame of the Passive House concept, Energy and buildings 37, 2005, pp 1186-1203.

[11] C. Isaksson \& F. Karlsson, Indoor Climate in Low-energy Houses - An Interdisciplinary Investigation, Building and Environment 41, 2006, pp 1678-1690.

[12] Empirical data (2002 \& 2005) Members from 20 households took part in the study: 1. Alva 02 \& 05, Alf 02 \& 05, 2. Gunilla 02, 3. Hanna 05, Hannes 05, 4. Lisa 05, 5. Karl 02, Karin 02 \& 05, 6. Maria 02, Marcus 05, 7. Paulina 02 \& 05, 8. Rickard 02 \& 05, Rakel 02 \& 05, 9. Ville 02 \& 05, Vera 02 \& 05, 10. Caroline 02, Christer 05, 11. Daniela 02, David 02, 12. Frida 02, Fredrik 05, 13. Elin 05, Edvin 05, 14. Ida 02 \& 05, Isak 02 \& 05, 15. Johanna 02, 16. Nina 02, 17. Sandra 05, 18. Oda $02 \&$ 05, 19. Tea 02 \& 05, 20. Ulla 02.

[13] S. Kvale, Den kvalitativa forskningsintervjun (The Qualitative research interview) Studentlitteratur, 1997.

[14] E. Shove, Comfort Cleanliness Convenience. The Social Organization of Normality, Berg, 2003.

[15] J.F. Nicol \& M.A. Humphreys, Adaptive thermal comfort and sustainable thermal standards for buildings, Energy and buildings 34, 2002 pp 563-572.

[16] C. Isaksson, The Absence of a Conventional Heating System -From the Perspective of the Occupants, Proceedings ECEEE 2005 Summer study Energy savings: What Works and Who Delivers?, Panel 6, 2005, pp 1221-1230.

[17] H. Wilhite, N. Hidetoshi, T. Masuda, Y. Yamaga, \& H. Haneda, A cross-cultural analysis of household energy use behaviour in Japan and Norway, Energy Policy 24, 1996, pp 795-803.

[18] B. Berner, Working knowledge as performance: on practical understanding of machines, Work Employment \& Society 22, 2008, pp 319-336.

[19] M. Bakardjieva, Domestication running wild. From the moral economy of the household to the mores of a culture, in T. Berker, M. Hartmann, Y. Punie \& J. K. Ward (eds), Domestication of Media and Technology, Open University Press, 2006, pp 62-79. 